\title{
Development of mountain peatlands in stable equilibrium with open-channel hydraulics: A new concept in peatland formation and maintenance
}

\section{Rachel Nanson}

Geography and Environmental Studies, Level 9 Napier Building, University of Adelaide, Adelaide, SA rachel.nanson@adelaide.edu.au

\section{Introduction}

Peatlands are often perceived to be relatively fragile ecosystems that are sensitive to fluctuating water tables and disrupted by channel formation. The Barrington Tops region of New South Wales exhibits peatlands and channels that have coevolved to form stable equilibrium systems not previously recognised in upland systems. The channels have adjusted their cross-sections, bedforms and planform to optimise flow efficiency and limit vertical peatland development. This research summarises these conditions for several peatland channels.

High channel bank strength is afforded by dense vegetation that facilitates optimal hydraulic efficiencies with unusually low channel width/depth ratios of $\sim 2$. Such channels frequently flow at or close to bankfull but rarely flow overbank, an unlikely coincidence unless the channels and the peatlands coevolved. Shear stress calculations suggest that bankfull flows are more than capable of transporting the scant sediment load but planform and bedform adjustments consume surplus energy and minimise erosion, resulting in highly stable, flowefficient channels.

Polblue Creek, Barrington River and Edwards Creek have each developed sinuous planforms, with some examples of very tight bends. The reduction in energy gradient resulting from sinuous planform development and the substantial turbulence that these tight bends generate combine to partly counter the exceptional hydraulic efficiency of the narrow and deep channel cross-sections.

Bedform magnitude (steepness) is strongly linked to flow resistance and there are large variations in the scale of bedforms in the channels studied here. In the smaller but more sinuous Polblue Creek, power is moderate and bed features display only moderate steepness values. In contrast, the larger but less sinuous Barrington River and Edwards Creek channels have higher stream powers and their armoured bedforms have developed with much greater 
steepness. The considerable turbulence associated with sinuous planforms and large wellarmoured bedforms are sufficient to generate the energy losses required to maintain channel and peatland stability.

Once peatland channels have attained their most efficient cross-sections for the evacuation of water from the peatland, any further (vertical) growth of the peatlands is restricted by enhanced flow velocities and limited flow depths; the volume of peat in such peatlands is determined by the hydraulic efficiency of their channels. The development and maintenance of the geometry of these peatland channels is bio-geomorphic and bio-hydraulic in nature and yet accords to the same optimising principles that govern the formation of self-adjusting channels with floodplains formed of clastic alluvium.

\section{Channelled peatlands}

Streams that flow through wetlands are usually sinuous and are bound by vertical organic and/or peat banks. Their beds are comprised of sand and gravel, peat or basement material (bedrock) and they tend to exhibit slot-like cross-sections. Some research has focused on the cross-sectional and planform geometry of such organic streams (Jurmu and Andrle 1997; Jurmu 2002), however little research has examined their geometry-flow interactions and the relationship between the channels and their associated peatlands.

The expected response of a peatland to channel incision is that as the water table is lowered, existing vegetation is greatly modified and fluctuations within the peatland water table increase (Price et al. 2003). Peatlands can become dewatered and compacted following such incision (Johnston and Brierley 2006), with consequent impacts on peatland hydrology, floristics (e.g. Southern 1982; Hope 2003) and sedimentology. The recent history of Sphagnum peatlands in southern Australia shows that increased drainage can convert Sphagnum bog to grasslands or sedgelands (Good 1992). However, while peatland vegetation might be replaced by more terrestrial species, over a longer timeframe the cycle of peatland development can recommence (Young 1986b). While peatland ecology is likely to be severely altered by the development of channelled conditions (Price et al. 2003), the development of channelled peatlands does not necessarily imply non-equilibrium systems. Some peatlands appear to have co-evolved with the channels that occupy them and the palynological record is hence a record of both peatland geomorphology and climate.

In order to maintain a highly organic peatland, bankfull flows need to be relatively frequent or the vegetation at the surface of the peatland will die; peatland vegetation is highly dependent on the level of the water table. At Barrington Tops, New South Wales, bankfull flows were observed many times each year, during the 2002-2004 field seasons, and channels showed remarkably uniform maximum capacities along their length. Furthermore, significant overbank flooding during these peak rainfall events was rare and spatially isolated. This would be a remarkable coincidence if the channels and peatlands had not co-evolved. Once the channels have attained an optimal cross-section through the vertical accretion and growth of a system of inset floodplains (Nanson 2009), further growth of the peatland vertically, which is highly water dependent, is limited by bankfull stage height (Nanson et al. 2010).

This research summarises recent investigations into the evolution, morphology and flow hydraulics of several peatland streams that flow through two upland peatlands on the Barrington Tops plateau (Figure 1a). 
a.

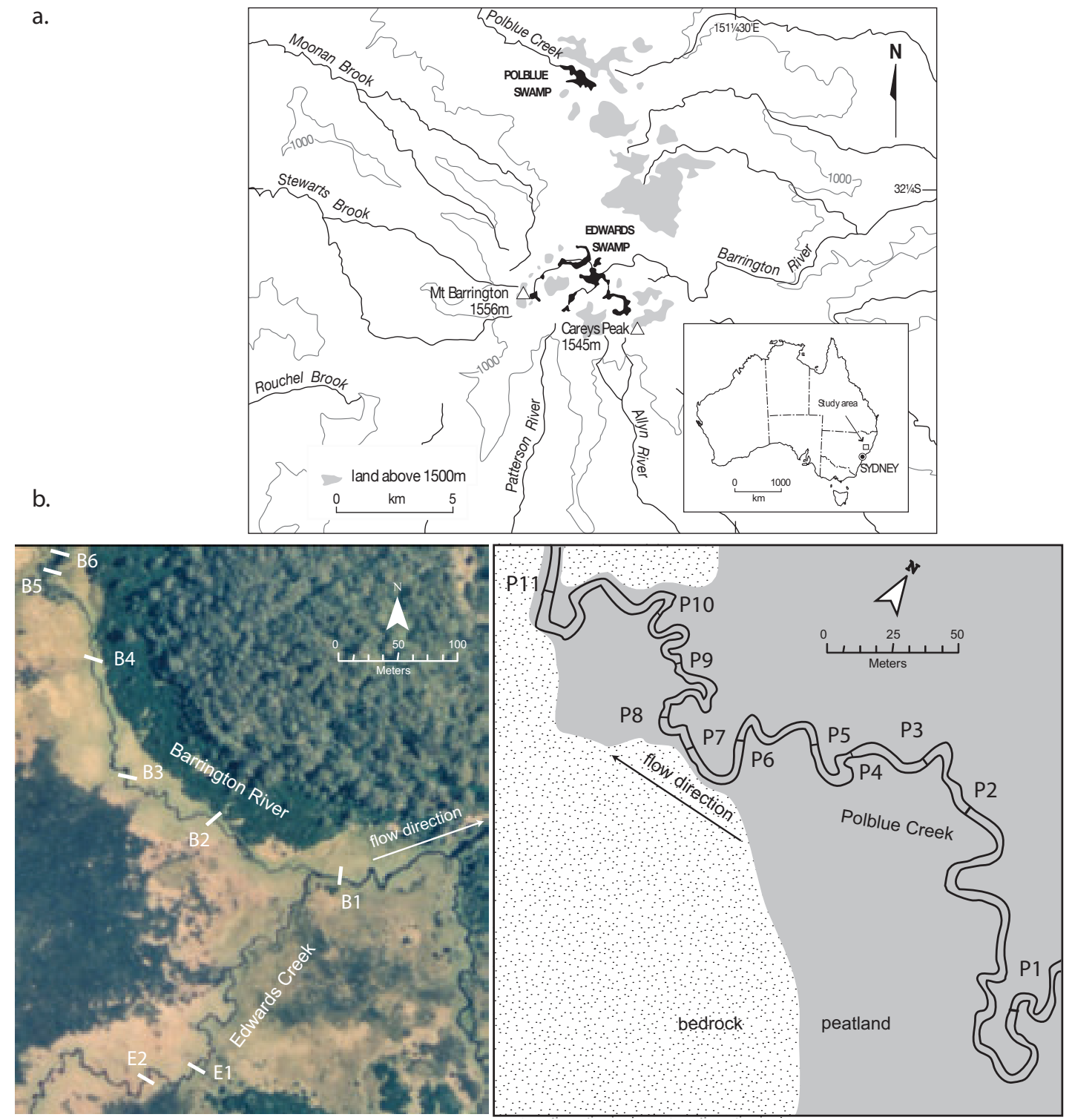

Figure 1. Location of (a) the Barrington Tops (modified from Dodson 1987) and (b) the peatland channels. Hydraulic geometry stations are indicated for Polblue Creek (P), Barrington River (B) and Edwards Creek (E)

\section{Barrington Tops}

\section{Regional setting}

The channels and peatlands of the Barrington Tops are situated on a $1000 \mathrm{~km}^{2}$ upland plateau $\sim 1500 \mathrm{~m}$ above sea level. The plateau is situated approximately $200 \mathrm{~km}$ north of Sydney and incorporates both the Barrington Tops National Park (New South Wales National Parks and Wildlife Service) and the Barrington Tops Reserve (New South Wales State Forests). Mean annual precipitation, in the form of rain, fog and snow, reaches $2000 \mathrm{~mm}$ in areas over $700 \mathrm{~m}$ asl. (Zoete 2000). The western slopes rise $-1000 \mathrm{~m}$ in fewer than $8 \mathrm{~km}$. As a result of its high altitude and steep terrain, the region is subject to severe weather fluctuations. At $1300 \mathrm{~m}$ asl, average July temperatures range from $-2.3^{\circ} \mathrm{C}$ to $8.8^{\circ} \mathrm{C}$ and January temperatures from $9.1^{\circ} \mathrm{C}$ to $22.8^{\circ} \mathrm{C}$ (Tweedie 1963). Areas above $1100 \mathrm{~m}$ asl experience up to five snowfalls each year, generally up to $\sim 0.2 \mathrm{~m}$ deep (Zoete 2000). 
Montane peatlands and swamps have formed in the broad, flat hollows (Dodson 1987) of this sub-alpine environment (Figure 1b) and are listed as Threatened Ecological Communities by the Department of Environment and Conservation (NSW). Many of the Barrington peatlands have developed meandering channels and this research specifically examines three such channels in the Polblue (1480-1500 m asl) and Edwards (1400-1420 m asl) swamps. These are Polblue Creek, Barrington River and Edwards Creek (Figure 1b). Each of these channels drain sub-catchments approximating $4 \mathrm{~km}^{2}$, and Edwards Swamp is collectively supplied by $8 \mathrm{~km}^{2}$ of catchment as it is situated at the confluence of both Edwards Creek and the Barrington River. Polblue and Edwards swamps cover areas of approximately 0.5 $\mathrm{km}^{2}$. However, elongated arms of Edwards Swamp extend further up both tributaries of that swamp. The vegetation of the peatlands are either Sphagnum hummock-hollow communities or Cyperaceae-Restionaceae sedgelands, surrounded by Poa sieberana and Epacris paludosa in better-drained locales (Dodson et al. 1986; Dodson and Myers 1986). The beds of the channels are sparsely vegetated with several ribbon-weed species, but these were not collected for taxonomic identification.

\section{Channel evolution}

Peatland channels in peatlands at Barrington Tops typically have narrow and deep crosssections, near-vertical resistant banks, relatively flat beds and almost perfect symmetry (Figure 2). Despite remarkably frequent bankfull flow, they transport almost no bedload (Nanson 2006) and therefore exhibit low width/depth ratios close to the optimum for transporting water alone (Chow 1959; Huang et al. 2002; Huang et al. 2004). That these channels frequently accommodate bankfull flow and rarely flood overbank prompted Nanson (2006) to suggest that they may be self-forming systems adjusted to contemporary flow conditions. Many peatland environments have long been subject to direct (e.g. draining) and indirect (e.g. fires) land-use pressures (Mitsch and Gosselink 1986). Furthermore, the draining of many peatlands and valley fills post-European settlement in Australia is well documented (e.g. Eyles 1977; Fryirs and Brierley 1998) and the possibility has been considered that the peatland channels of the Barrington Tops may be anthropogenically caused. However, Nanson (2009) dated inset floodplain (peat) units and presented palynological data which demonstrated that, while the peatlands themselves (upper floodplains) commenced accumulation before at least 5.4 ka (Polblue Swamp, Dodson et al. 1986) and 3.6 cal. BP (Edwards Swamp, Nanson 2009), over the past -1000 years the channels have reduced in size from larger channels or gullies that were formed during a different flow regime. These channels are flanked by inset floodplains. While in places the channels are somewhat depth-constrained by a resistant basement to the peatlands, they are otherwise essentially free to adjust their cross-sectional and planform geometry within a matrix of peat. For this reason, these channels and inset floodplains are considered to adopt the self-adjusting equilibrium conditions widely described for alluvial channels and their floodplains.

\section{Channel hydrology}

Further support for the evolutionary link between the Barrington peatlands and the streams that flow through them is indicated by channel-flow hydrograph analyses.

Andeera Water Level Recorders were deployed in each peatland during two three-week field trips, the first during November/December 2003 (early summer) and the second during May/ June 2004 (early winter). The most significant water-level rises were, not unexpectedly, directly linked to rainfall events, the steep rising limbs of the hydrographs confirming this observation. When the flow-stage time-series data for summer flows are detrended (using an additive decomposition), a dominant (statistical) seasonal-cycle of diurnal fluctuations is exhibited by both peatland channels (Figure 3). Channel flow stages fluctuate through $0.06 \mathrm{~m}$ and $0.05 \mathrm{~m}$ 
Polblue Creek

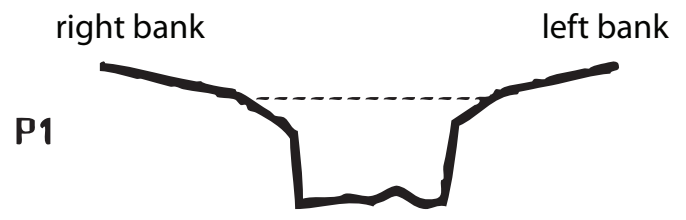

P2

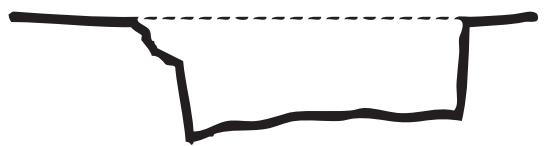

P3

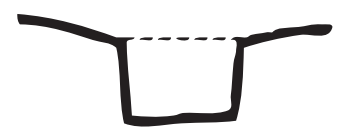

PA

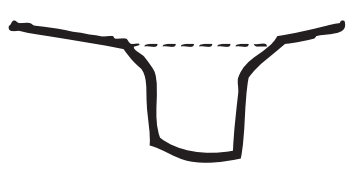

P5

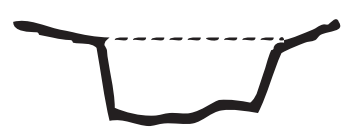

P6

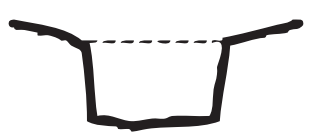

P7

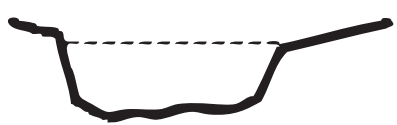

P日

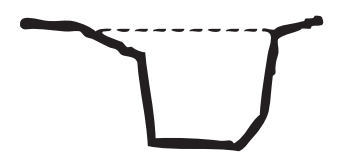

P9

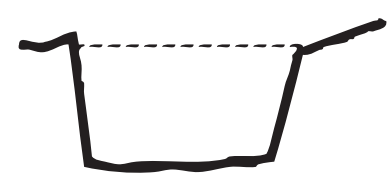

P10

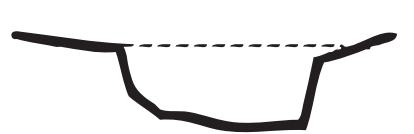

P11

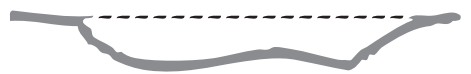

Barrington River

B1

B2

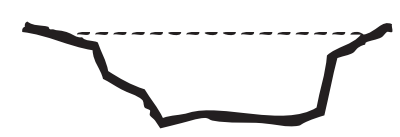

B3

BA

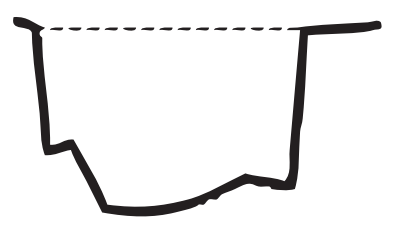

B5
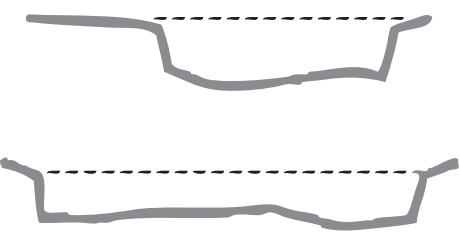

B6

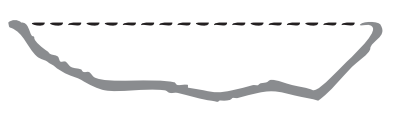

\section{Edwards Creek}

E1

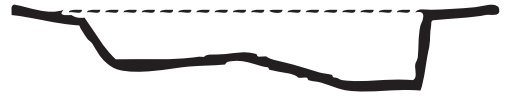

E2

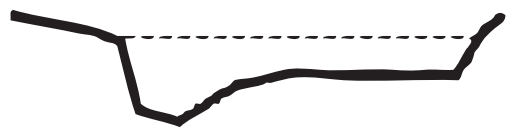

$1: 1$

Bankfull flow

Figure 2. Hydraulic geometry station cross-sections. Flow is towards the reader, out of the page. Grey cross-sections indicate those near entry and exit locations to each peatland

seasonal cycles in Polblue Creek and the Barrington River, respectively. In both channels, flow reached its maximum stage at approximately $6 \mathrm{am}$, immediately before sunrise, from which time it dropped until $\sim 2 \mathrm{pm}$, levelled off and then rose again until $\sim 10 \mathrm{pm}$. From then until midnight, the pattern plateaued, then rose again until 6am. 


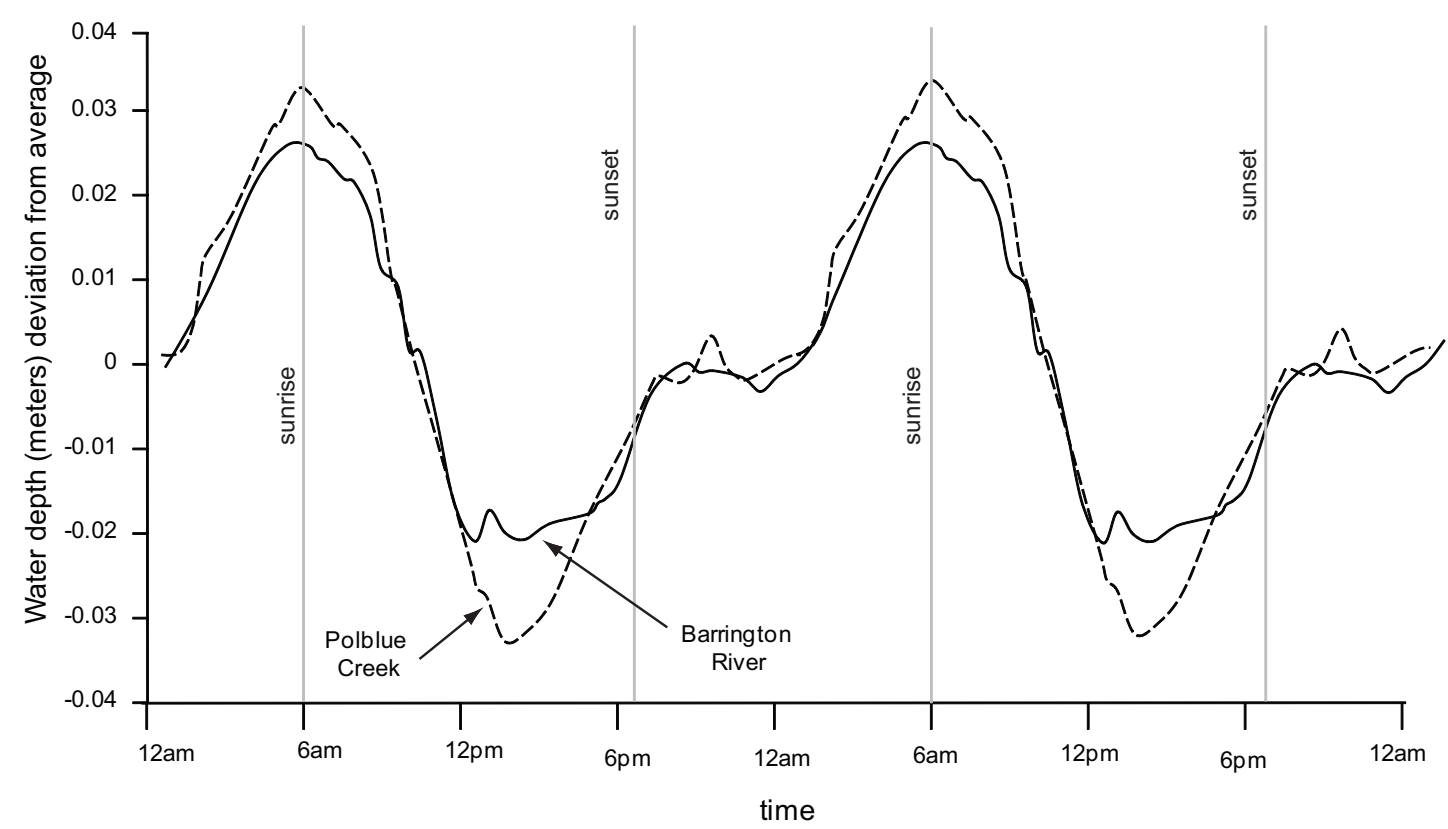

Figure 3. Average seasonal (daily detrended) flow stage variations in Polblue Creek and the Barrington River for selected days recorded in summer (2003)

Daylight and/or temperature has a clear impact on summer flow fluctuations in the Barrington peatland channels, consistent with the (statistically) seasonal variations described by Todd (1964). Day-time losses in channel flow may well be related to the drawing of water from the channels into the surrounding peatlands by plants during daylight hours, when evapotranspiration is at a maximum (Todd 1964; Mitsch and Gosselink 1986). As the plants' need for water reduces during night-time hours, particularly between the hours of midnight and 4am (Todd 1964) (or 6am in the Barrington peatlands), the pressure gradient is reversed towards the channel, thereby increasing flow-stage.

Furthermore, the Barrington Tops channelled peatlands illustrate healthy vegetation, and systematic exchange has been indicated between the channels and peatland-floodplain water table. If the channel water levels were not balanced with the peatland water table, then it is expected that the peatland vegetation would die. That the hydrological balance between the peatlands and the channels is so satisfactory to both peatland vegetation and bankfull flow frequency implies the stability of both features. Furthermore, this balance indicates the importance of channel morphology in determining peatland depth. Channel morphology determines flow-stage height, which, in turn, determines the height of the peatland water table. The peatland water-table height controls peatland growth, in a manner that closely imitates the link between more conventional alluvial channels and their adjacent floodplain growth by overbank sedimentation.

\section{Barrington peatland channel geometry and hydraulics}

It is widely accepted that self-forming alluvial streams are adjusted towards what are broadly termed 'equilibrium conditions'. G.K. Gilbert recognised this in his seminal work (1914) but Mackin (1948) enunciated the concept clearly in his classic paper, focusing primarily on the river's ability to adjust channel slope, and described such adjusted rivers as 'graded'. His definition was subsequently expanded by Leopold and Bull (1979) to summarily include adjustments in velocity, roughness, channel pattern and cross-sectional morphology and slope. 
The evolution of a channel towards a stable endpoint, therefore, involves the adjustment of all three morphological elements - cross-section (examined through hydraulic geometry), bedform and planform - and can be assessed through an examination of water surface slope (Figure 4).

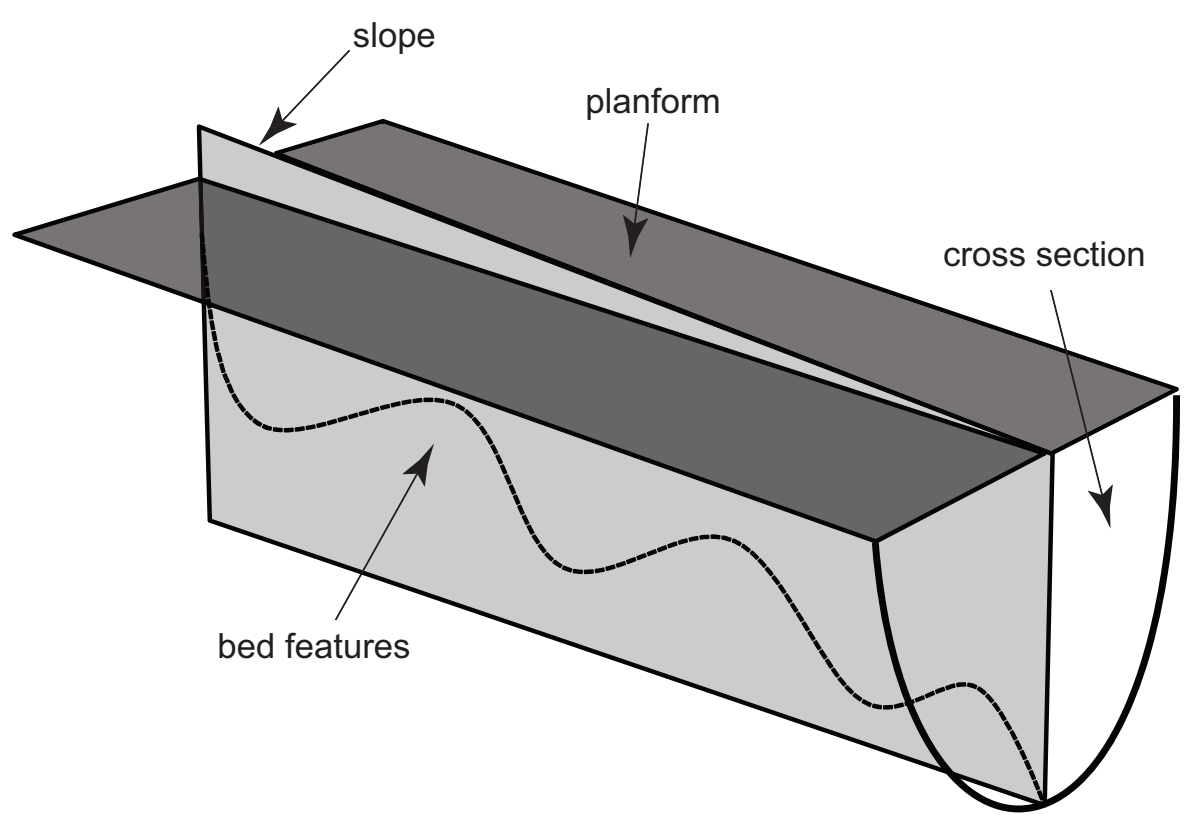

Figure 4. Morphological elements and planes of channel adjustment, modified from Knighton (1998)

\section{Hydraulic geometry}

Hydraulic geometry is essentially used to represent the rate of change in channel width, depth and flow velocity with increasing flow discharge, i.e. the proportions of these three variables that accommodate increased discharge. This is expressed as:

$$
\begin{aligned}
& \mathrm{w}=\mathrm{a} \mathrm{Q}^{\mathrm{b}} \\
& \mathrm{d}=\mathrm{c}^{\mathrm{f}} \\
& \mathrm{v}=\mathrm{kQ}^{\mathrm{m}}
\end{aligned}
$$

where

$$
\mathrm{Q}^{1}=\mathrm{aQ}^{\mathrm{b}} \mathrm{cQ}^{\mathrm{f}} \mathrm{kQ}^{\mathrm{m}}
$$

$\left(\mathrm{w}=\right.$ width, $\mathrm{d}=$ depth, $\mathrm{v}=$ velocity and $\mathrm{Q}=$ discharge $\left.\left(\mathrm{m}^{3} / \mathrm{s}\right)\right)$.

Hydraulic geometry can be considered at a station as a rising flow fills a channel cross-section, or in a downstream direction as the bankfull channel dimensions expand to accommodate increasing catchment runoff (termed bankfull hydraulic geometry). Such measures have traditionally been used to understand or characterise the regional setting (Park 1977; Rhodes 1977), and the sediment transport dynamics or bank strength of a fluvial system, or to investigate more complex theoretical considerations of equilibrium fluvial forms (e.g. Yang 1971; Pickup 1976; Nanson and Huang 2008).

Nanson et al. (2010) measured at-a-station and bankfull hydraulic geometry at 19 temporary gaging stations along three of the Barrington peatland channels. They reported 
average at-a-station hydraulic geometry exponents for the study streams for width (b), depth (f) and velocity (m) of $0.05,0.35$ and 0.60 , respectively. These results indicate that with changing at-a-station discharge, rapid changes in velocity are accompanied by moderate changes in depth and almost no change in width.

Despite some constraint on channel depth $(f=0.35)$, caused by a limited depth to basement at a number of locations where periglacial cobble lobes extend into the peatland mid-basin, most of the gaged stations have near vertical banks, at-a-station and bankfull width exponents approaching zero and width/depth ratios of $\sim 2$. The geometry of these channels is certainly partly due to remarkably high bank strength, and hence the botanical influence on channel form is unusually high compared with alluvial channels. While in most alluvial systems increases in discharge are accommodated primarily by increases in width and to a lesser extent depth, in the Barrington peatland channels, these variables are more constrained and discharge adjustments are accommodated largely by high rates of increase in velocity $(\mathrm{m}=0.60)$.

The Barrington peatland channels are essentially free of sediment transport. While Huang et al. (2004) suggested that, despite such narrow geometries of $\sim 2$ being theoretically optimal for sediment-free rectangular channels in equilibrium, insufficient bank strength in natural streams greatly limits their occurrence. Nanson et al. (2010) have shown that peatland channels can indeed provide such optimal conditions. At some locations along the Barrington peatland streams, large bedforms of sand and pebbles do occur, but even at high flows there is almost no bed-sediment movement. The role that these bedforms play in dampening such high rates of velocity increase is discussed below.

\section{Bed features}

Nanson (2006) analysed survey data along the channel thalweg to investigate the role bed features play in regulating channel energy. Bed feature steepness (wavelength/height, St) is proportionate to flow resistance (Robert 2003); high St indicates high flow turbulence and hence high flow resistance. Three bed-feature types were identified on the basis of St values.

Entry and exit reaches to each of the peatland systems exhibit wider and shallower crosssections as the channels flow over shallow basalt and granite outcrops and demonstrate the lowest hydraulic efficiency of the sample channels. Nevertheless, bed shear stresses through these reaches were shown to exceed the critical values required for the transport of sand and silt, if any were present. St values were not calculated for these reaches as bed feature spacing was unsystematic.

In deeper peat reaches of the peatlands, such as along much of Polblue Creek, a second type of low amplitude pool-riffle bedform $(S t<0.03)$, mostly derived of massive and cohesive clay, has developed. These provide little resistance to flow (Nanson 2006), and are present throughout reaches with highly efficient channel cross-sections. Through such exceptionally narrow channel reaches (width/depth -2 ), the majority of the flow resistance is provided by the banks, and these were shown to severely reduce the sediment-transporting ability of the channels (Nanson 2006). Nevertheless, sufficiently high rates of increase in velocity through these reaches (Nanson et al. 2010) indicate high sediment-transport capacities and sufficient bed shear stress to transport bedload, should there be any; however, very little was observed. These channels are therefore supply, rather than transport, limited. The strength of the channel banks is, therefore, clearly sufficient to resist flow forces without the necessity of developing energy-reducing bedforms in these reaches.

The third category of bedform was identified along the larger Edwards Creek and midBarrington River reaches, where sediment supply has, at some stage or over a long enough period of time, been sufficient to construct very large bedforms that are intermediate between dunes and riffles (Nanson 2006). These features are associated with the tightest bends and are 
scaled to channel planform and width, consistent with pool-riffle sequences. However, they are also very steep features ( $\mathrm{St}>0.06$ ), more consistent with mobile bedforms such as dunes. These reaches are otherwise very hydraulically efficient (width/depth -2 ). Nanson (2006) calculated that the shear stresses available for sediment transport (and channel erosion) were severely reduced in these higher-discharge channels by the presence of these bed features. High bank strengths, aquatic vegetation and armouring (of fine sediment by coarser surficial sediment) of their beds has ensured the stability of these bed features despite the large turbulent flow structures they produce (Nanson 2006). Their effect on hydraulic geometry is subdued rates of velocity increase with increasing at-a-station discharge (Nanson et al. 2010).

The apparent lack of sediment supply and the armouring and partial aquatic vegetative cover of the steepest bed features indicate that these bedforms could be vulnerable to disturbance. These bed features presumably formed rapidly following channel incision into the peatlands. Loss of bed armouring or disturbance of the vegetation could result in greatly increased mobility of the bed sediment, as subsurface materials are more easily entrained by the grain shear stresses available. Because these catchments do not have a ready supply of sediment, disturbance to these steep bed features would very likely result in a decrease in flow resistance and a concomitant increase in bed, and possibly bank, erosion.

\section{Planform}

Using the concept of minimum stream power, Bettess and White (1983) described how channel planform adjusts from straight to meandering (to braided) in order to create a balance between the regime channel slope, defined as that slope required for the equilibrium transport of the supplied sediment, and the valley slope. Channels in which regime slope coincidentally equals valley slope are straight and very rare, whereas valley slopes in excess of the required regime slope are common and result in either meandering or braiding planforms. Channels meander for two reasons, both of which directly impact on channel energy: one, to reduce channel slope and hence the energy gradient (Langbein and Leopold 1966; Bettess and White 1983); and two, to provide bend flow resistance through the development of secondary circulation and turbulent flow structures and thereby consume energy (Leopold et al. 1960; Langbein and Leopold 1966) and facilitate the most probable distribution of channel energy in accordance with the theory of minimum variance (Langbein and Leopold 1966). The more sinuous the channel, the greater the reduction in slope (potential energy) and the greater the loss of (kinetic) energy due to internal distortion of the flow-through bends.

Channel sinuosity $(\mathrm{P})$ is a measure of the length of channel divided by the straight line length of valley; the Barrington peatland channels vary from $\mathrm{P}=1.05$ (very straight) to $\mathrm{P}=$ 1.98 (very sinuous) (Nanson 2006). Bend radius of curvature to width ratios also provide an indication of sharpness of channel bend curvature relative to channel size and Nanson (2010) examined bends varying from 2.4 to as low as 0.6 , demonstrating unusual threedimensional bend flow patterns resulting from interactions between various combinations of particularly low width-depth ratio cross-sections, steep bedforms and over-tightened bends. Most importantly, very low radius of curvature to width ratios indicate exceptionally high energy losses. The narrow deep peatland channels at Barrington Tops offer maximally efficient cross-sections and such extreme sinuosity is necessary to consume the resulting surplus energy and maintain channel stability.

A relationship between a proposed flow-resistance proxy, the product of sinuosity (P) and bedform steepness ( $\mathrm{St}$ ), and a proposed flow-efficiency term, the depth-width ratio, is presented in Figure 5. The uppermost point in this figure represents two overlapping stations from Edwards Creek and, for reasons discussed below, these plot as outliers. If these are removed from the dataset, the Barrington River and Polblue Creek stations illustrate a linear 


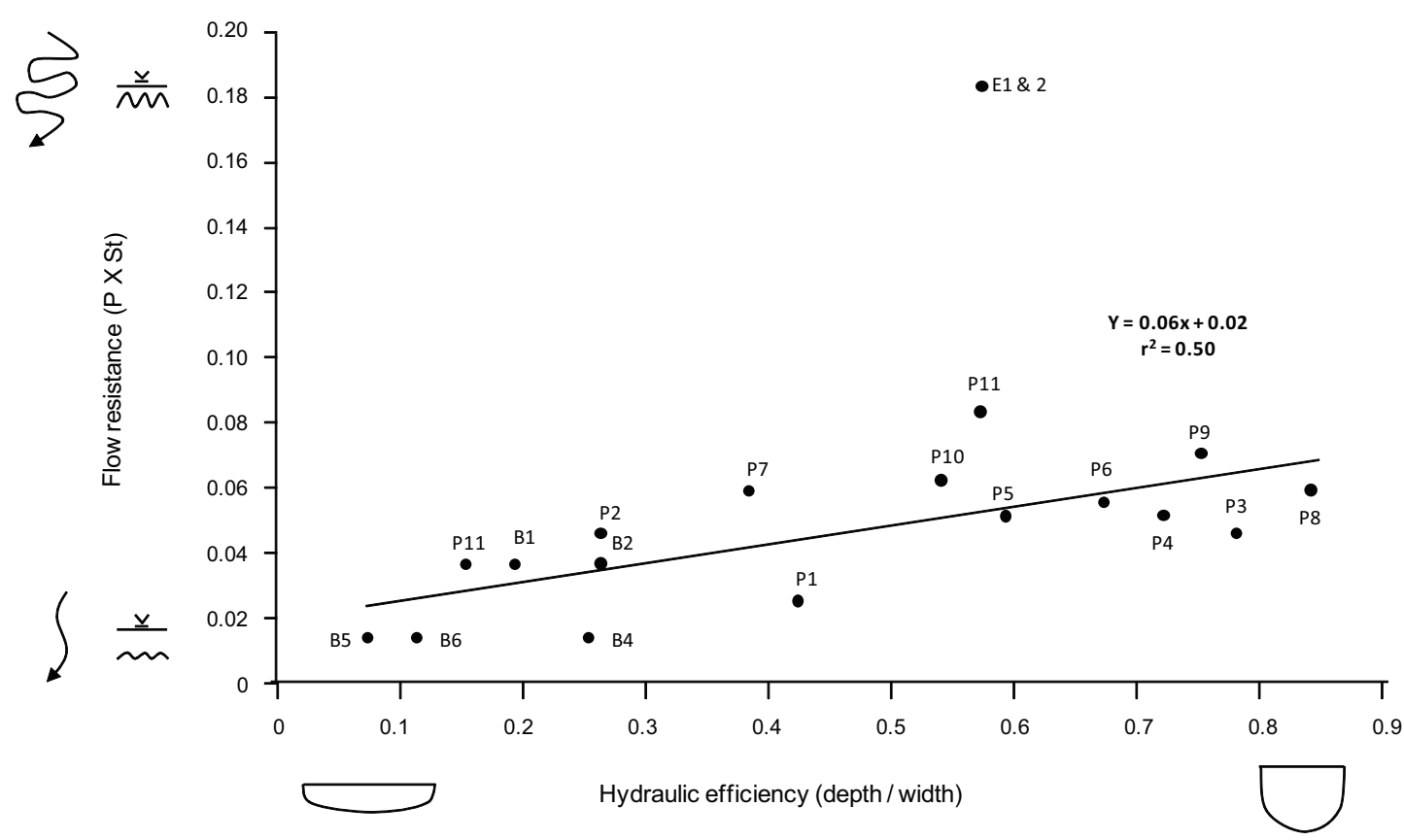

Figure 5. Stations with low hydraulic efficiency have similarly low flow resistance (bottom left of plot), whereas channel sections with higher hydraulic efficiency (upper right) illustrate that flow resistance elements have developed to partially counter such efficiency

relationship, with an $\mathrm{r}^{2}$ of 0.50 . Cross-sectional efficiencies of the channel stations are positively related to their associated measures of flow resistance, at a rate of 0.06 times efficiency.

Stations that plot in the lower-left region of the graph are located at entry and exit points of the peatlands - they are wide and shallow with low cross-sectional efficiency. Their planforms are therefore straight, as there is little surplus energy to consume, and they have only subtle bedforms that generate little roughness. Stations towards the right-hand side of the plot experience greater cross-sectional hydraulic efficiency and the channel response to consume excess energy and maintain stability is to increase sinuosity or bedform development, or both. Outlier Stations (E1 and E2) have very steep bed features $(\mathrm{St}=0.11)$ and are located along highly sinuous reaches, resulting in exceptionally high flow resistance.

\section{Assessment of the graded profile}

Entropy is a thermodynamic quantity representing the amount of energy in a system that is no longer available for doing work (Leopold and Langbein 1962; Chorley and Kennedy 1971) and considers the distribution of available energy within a system. The principle was first applied to fluvial environments by Leopold and Langbein (1962), in an effort to produce definitive equations for the solution of hydraulic geometry through the application of two principles: least work and maximum probability. They stated that (pp11 and pp7, respectively): 'the equilibrium profile of the graded river is the profile of maximum probability and the one in which entropy is equally distributed' and 'the most probable distribution of energy exists when the rate of gain of entropy in each interval of length along the river is equal'. Over an unconstrained length of channel, they concluded that the most likely form is exponential in long profile. However, over a more moderate length of stable channel that is neither aggrading (which might cause backwater effects) nor degrading, it follows that the energy of an equilibrium river (which is represented by the energy grade line and approximated by the bankfull water surface slope) should be evenly distributed and represented by a straight line. 
Mackin (1948) stated that the length of channel constituting a graded (equilibrium) system is not fixed in length. Herein, the graded condition is considered within the channelled reaches of each peatland that lie between constrictive lobes of shallow basement material, as it is these reaches, and their interaction with the peatland, that have the ability to self-adjust as equilibrium systems.

Figure 6 illustrates longitudinal profiles of the bankfull water surface for each of the three peatland channels. The entire study reach for more than $460 \mathrm{~m}$ of Edwards Creek shows a water-surface slope with an almost linear relationship and an $\mathrm{r}^{2}$ of 0.99 . The $180 \mathrm{~m}$ reach of the Barrington River, downstream of its confluence with Edwards Creek, also demonstrates a very even water-surface profile with an $\mathrm{r}^{2}$ value of 0.98 , and the middle reach of $370 \mathrm{~m}$ of Polblue Creek has a similarly constant gradient with an $\mathrm{r}^{2}$ value of 0.99 .

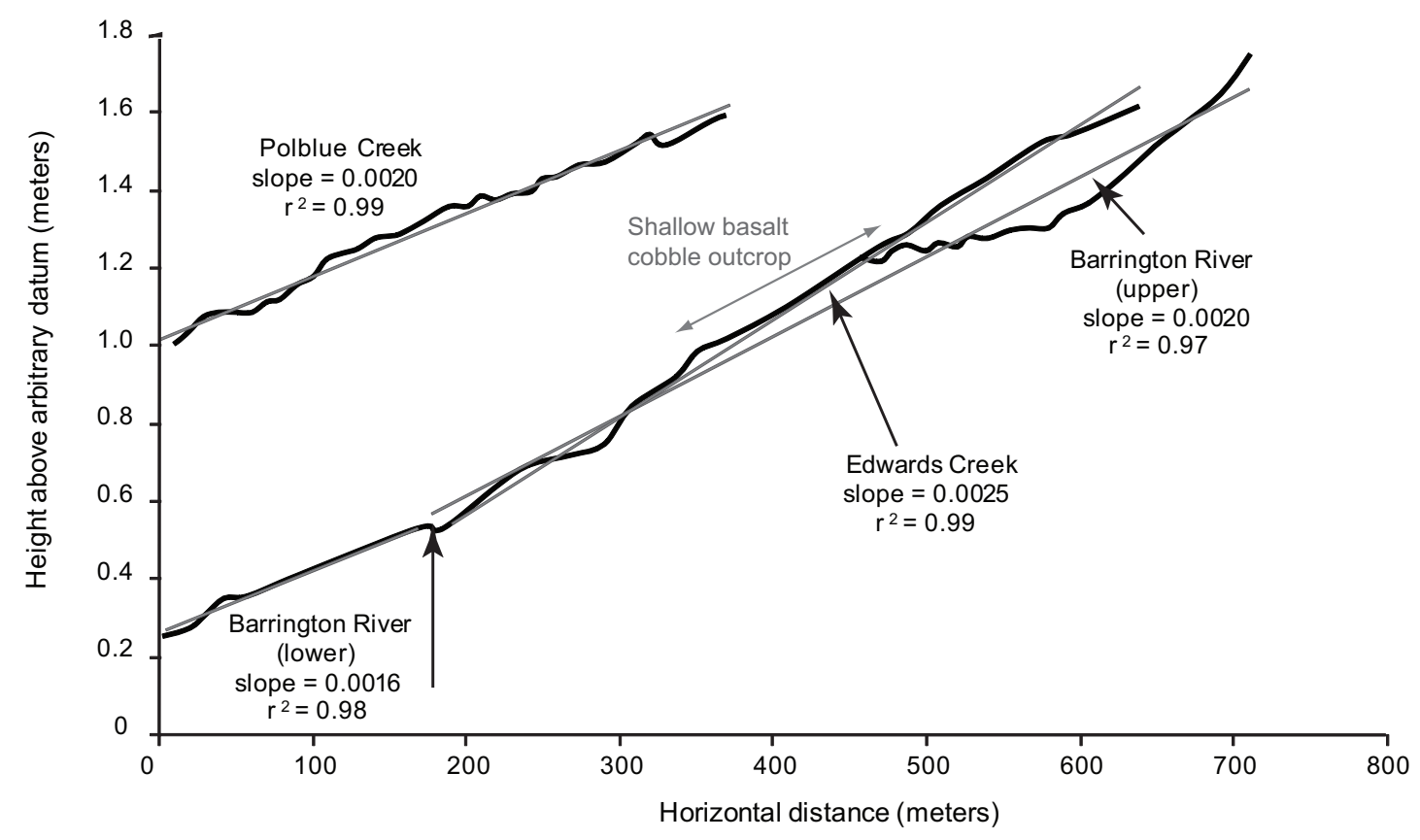

Figure 6. Bankfull (Iongitudinal) water-surface profiles. The regression lines along the Barrington River Upper and Edwards Creek terminate to the right of the vertical arrow

Nanson (2006) demonstrated that deviations from linear longitudinal water-surface profiles along the Barrington peatland channel water-surface profiles are the direct result of limiting peat depths at entry and exit reaches to the peatlands, or where the channels flow over shallow lobes of basalt or granite cobbles and boulders. It would appear that, when not constrained by a shallow basement, peatland channels are able to adjust to the most probable distribution of energy whereby variance is held at a minimum and the rate of gain of entropy in each interval of channel length is equal.

\section{Conclusions}

In the Barrington peatlands, narrow, deep and steep-banked channels provide optimal conditions for the hydraulically efficient flow of sediment-free water, consistent with the principal of minimum energy. The development of meanders in these peatland channels appears to have been sufficient, in the absence of bedforms in most reaches, for the attainment of channel stability. Leopold et al. (1960 pp131 and pp132, respectively) stated that 'a river which is deficient of bed material of large enough size to stabilise a straight channel may become stabilised 
in an irregular channel merely by creating random bank projections', and 'the meander form may represent one of the channel patterns to which the above generalisation applies, only the random bank projections are replaced by somewhat symmetrical channel curves'.

In the higher stream power channels (Edwards Creek and Barrington River), where very steep bedforms have developed, sediment must have either been supplied more readily at some time in the past, perhaps immediately following channel incision, or accumulated very slowly from minimal supply and transport rates. Where sediment has been sufficient, and where additional resistance has been required for channel stability in higher stream power systems, bedforms ranging from negligible (in most instances) to extremely large indicate a tendency for the channels to form flow-resisting elements in the vertical plane. Furthermore, channel sinuosities have developed from nearly straight to intensely sinuous, thereby illustrating the freedom for these channels to adjust in the lateral plane to achieve equilibrium. However, the presence of exceptionally tightly curving and stable meander bends at many locations indicates that the banks of the Barrington streams must be sufficiently resistant to erosion to maintain stability. Channels with more mobile banks would presumably erode and release sediment, form bedforms and consume energy more evenly between the bed roughness and the distortion of flow in bends.

Graded, almost linear, water-surface long profiles that extend over hundreds of metres in channels with almost no bedforms (Polblue), and higher stream power channels with exceptionally large bedforms (Edwards and Barrington channels) suggest that planform is closely integrated with other flow-resisting elements in order to maintain a condition of minimum variance and a uniform increase in entropy. Clearly, self-forming equilibrium channels can be generated and maintained in these densely vegetated, sediment-supply-limited and highly erosion-resistant peatland environments.

This research has demonstrated that the cross-sectional form of these peatland channels results in highly efficient flow conduits with velocities that increase sharply with increasing stage. The stability of such velocity-responsive peatland channels is dependent on two major factors: (1) high bank strength, provided by vegetation; (2) bedform strength, provided by sediment armouring and aquatic vegetation. The preservation of these two controlling parameters is integral to the continuing stability of both the channels and peatlands. If the very steep bedforms were to erode through the loss of armouring, limited sediment supply from upstream of the peatlands would inhibit their redevelopment. This research and that elsewhere (Nanson 2006; Nanson 2009; Nanson 2010; Nanson et al. 2010) suggests that loss of bedforms would result in a marked reduction in flow resistance and the destabilisation of the channel geometry. Likewise, the loss or significant alteration of riparian vegetation would have major implications for bank and bed strength and would also encourage changes in channel form and peatland hydrology. A feedback between stable, equilibrium channels and the surrounding peatlands is evident; there cannot be one without the stability of the other and the disruption of either would likely be to the detriment of both.

\section{Acknowledgements}

I would like to acknowledge funding from the following sources: the University of New South Wales at the Australian Defence Force Academy (UNSW@ADFA) University College Postgraduate Scholarship, the UNSW@ADFA Faculty Research Grants scheme, the School of Physical, Environmental and Mathematical Sciences (UNSW@ADFA) and the Australian Institute of Nuclear Science and Engineers (AINSE). I thank Geoff Hope, Gerald Nanson, Tim Cohen and Roger McLean for rewarding discussions and suggestions, Ben Keaney for pollen counting, and James Boyle, Paul Grevinitz and Tim Robinson for their assistance in the 
field. I also thank an anonymous reviewer for improving the manuscript. I acknowledge the National Parks and Wildlife Service (NSW) for issuing a scientific permit.

\section{References}

Bettess, R and W.R. White 1983. Meandering and braiding of alluvial channels. Proceedings of the Institution of Civil Engineers, Part 1: Design and Construction 75:525-538.

Chorley, R.J and B. Kennedy 1971. Physical geography, a systems approach. London: Prentice Hall.

Chow, V.T. 1959. Open-channel hydraulics. Singapore: McGraw-Hill Book Company.

Cohen, T.J. and G.C. Nanson 2007. Mind the gap: valley deposits and independant proxy climate data identifying the Holocene hypsithermal period of enhanced flow regime in southeastern Australia. Holocene 17:1-8.

Dodson, J.R. 1987. Mire development and environmental change, Barrington Tops, New South Wales, Australia. Quaternary Research 27:73-81.

Dodson, J.R., P.W. Greenwood and R.L. Jones 1986. Holocene forest and wetland vegetation dynamics at Barrington Tops, New South Wales. Journal of Biogeography 13(6):561-585.

Dodson, J.R. and C.A. Myers 1986. Vegetation and modern pollen rain from the Barrington Tops and Upper Hunter River regions of New South Wales. Australian Journal of Botany 34(3):293-304.

Eyles, R.J. 1977. Changes in drainage networks since 1820, Southern Tablelands, N.S.W. Australian Geographer 13(6):377-386.

Fryirs, K. and G. Brierley 1998. The character and age structure of valley fills in Upper Wolumla Creek catchment, South Coast, New South Wales, Australia. Earth Surface Processes and Landforms 23(3):271-287.

Gilbert, G.K. 1914. The transportation of debris by running water. United States Geological Survey Professional Paper 86:1-263.

Good, R.B. 1992. Kosciusko Heritage - The conservation significance of Kosciusko National Park. National Parks and Wildlife Service and Surrey Beatty and Sons, Chipping Norton, NSW.

Hope, G.S. 2003. The mountain mires of southern New South Wales and the Australian Capital Territory: their history and future. In: Janet Mackay and Associates (Ed.), Celebrating mountains: Proceedings of an International Year of Mountains conference, Jindabyne, Australia. Canberra: Australian Alps Liason Committee.

Huang, H.Q, H.H. Chang and G.C. Nanson 2004. Minimum energy as the general form of critical flow and maximum flow efficiency and for explaining variations in river channel pattern. Water Resources Research 40(4):1-13.

Huang, H.Q., G.C. Nanson and S.D. Fagan 2002. Hydraulic geometry of straight alluvial channels and the principal of least action. Journal of Hydraulic Research 40(2):152-160.

Johnston, P. and G.J. Brierley 2006. Late Quaternary river evolution of floodplain pockets along Mulloon Creek, New South Wales, Australia. Holocene 16:661-674.

Jurmu, M.C. 2002. A morphological comparison of narrow, low-gradient streams traversing wetland environments to alluvial streams. Environmental Management 30(6):831-856.

Jurmu, M.C. and R. Andrle 1997. Morphology of a wetland stream. Environmental Management 21(6): 921-941.

Knighton, A.D. 1998. Fluvial forms and processes: A new perspective. London: Arnold.

Langbein, W.B. and L.B. Leopold 1966. River meanders - theory of minimum variance. United States Geological Survey Professional Paper 422-H:H1-H15. 
Leopold, L.B., R.A. Bagnold, M.G. Wolman and L.M. Brush (Jnr) 1960. Flow resistance in sinuous or irregular channels. United States Geological Survey Professional Paper 282D:108-134.

Leopold, L.B. and W.B. Bull 1979. Base level, aggradation and grade. Proceedings of the American Philosophical Society 123(3):168-202.

Leopold, L.B. and W.B. Langbein 1962. The concept of entropy in landscape evolution. United States Geological Survey Professional Paper 500A:A1-A20.

Mackin, J.H. 1948. Concept of the graded river. Geological Society of America Bulletin 59(5):463-511.

Mitsch, W.J. and J.G. Gosselink 1986. Wetlands. New York: Van Nostrand Reinhold Company Inc.

Nanson, G.C. and H.Q. Huang 2008. Least action principle, equilibrium states, iterative adjustment and the stability of alluvial channels. Earth Surface Processes and Landforms 33(6):923-942.

Nanson, R.A. 2006. Stream channel adjustment in upland swamps, Barrington Tops, New South Wales, Australia. Unpublished Ph.D. Thesis, University of New South Wales at the Australian Defence Force Academy, Canberra.

Nanson, R.A. 2009. The evolution of peat-swamp channels and organic floodplains, Barrington Tops, New South Wales, Australia. Geographical Research 47(4):434-448.

Nanson, R.A. 2010. Flow fields in tightly curving meander bends of low width-depth ratio. Earth Surface Processes and Landforms 35:119-135.

Nanson, R.A., G.C. Nanson and H.Q. Huang 2010. Bio-geomorphology and hydraulic geometry of narrow and deep channels in peatland floodplains; evidence for optimisation. Geomorphology 117(1-2):143-154.

Park, C.C. 1977. World-wide variation in hydraulic geometry exponents of stream channels: an analysis and some observations. Journal of Hydrology 33(1-2):133-146.

Pickup, G. 1976. Alternative measures of river channel shape and their significance. Journal of Hydrology (NZ) 15(1):9-16.

Price, J.S., A.L. Heathwaite and A.J. Baird 2003. Hydrological processes in abandoned and restored peatlands: an overview of management approaches. Wetlands Ecology and Management 11:65-83.

Randell, F., D. Ellsmore, A. Messner, I. Brown, G. Bubb and Low and Hooke 2003. Contextual history for the Barrington Tops National Park and heritage action statements for five huts within the park, NSW National Parks and Wildlife Service.

Rhodes, D.D. 1977. The b-f-m diagram: graphical representation and interpretation of at-astation hydraulic geometry. American Journal of Science 277(1):73-96.

Robert, A. 2003. River Processes: An introduction to fluvial dynamics. London: Arnold.

Southern, W. 1982. Late Quaternary vegetation and environments of Jackson's Bog and the Monaro Tablelands, New South Wales. Masters Thesis, Monash University, Melbourne.

Todd, D.K. 1964. Groundwater. In V.T. Chow (ed.) Handbook of applied hydrology: A compendium of water-resources technology, pp13/1-55. New York: McGraw-Hill.

Tweedie, A.D. 1963. Climate of the Hunter Valley. CSIRO Australian Land Research Series 8:62-70.

Yang, C.T. 1971. Potential energy and stream morphology. Water Resources Research $7(2): 311-322$

Young, A.R.M. 1986a. The geomorphic development of dells (Upland Swamps) on the Woronora Plateau, N.S.W., Australia. Zeitschrift fur Geomorphologie 30(3):317-327.

Young, A.R.M. 1986b. Quaternary sedimentation on the Woronora Plateau and its implications for climatic change. Australian Geographer 17:1-5.

Zoete, T. 2000. Vegetation survey of the Barrington Tops and Mount Royal National Parks for use in fire management. Cunninghamia 6(3):511-578. 